\title{
Student effort expectations and their learning in first-year introductory physics: A case study in Thailand
}

\author{
U. Wutchana ${ }^{1}$ and N. Emarat ${ }^{2}$,* \\ ${ }^{1}$ Institute for Innovative Learning, Mahidol University, 999 Phuttamonthon 4 Road, Salaya, Phuttamonthon, \\ Nakhon Pathom 73170 Thailand \\ ${ }^{2}$ Department of Physics, Faculty of Science, Mahidol University, 272 Rama VI Road, \\ Bangkok 10400 Thailand
}

(Received 22 January 2010; published 24 June 2011)

The Maryland Physics Expectations (MPEX) survey was designed to probe students' expectations about their understanding of the process of learning physics and the structure of physics knowledgecognitive expectations. This survey was administered to first-year university students in Thailand in the first semester of an introductory calculus-based physics course during academic years 2007 and 2008, to assess their expectations at the beginning of the course. The precourse MPEX results were compared and correlated with two separate measures of student learning: (1) individual students' normalized gains from pre and post Force and Motion Conceptual Evaluation (FMCE) results, which measure students' conceptual understanding, and (2) student's scores on the final exam, which measure their more general problem-solving ability. The results showed a significant positive correlation between their overall MPEX score and five of the six MPEX cluster scores, with their normalized learning gains on the FMCE for both academic years. The results also showed significant positive correlations between student MPEX scores and their final exam scores for the overall MPEX score and all MPEX cluster scores except for the effort cluster. We interviewed two groups of five students each, one group with small favorable scores on the precourse MPEX effort cluster and one with high favorable scores on the precourse MPEX effort cluster, to see how the students' learning efforts compared with their MPEX results. We concluded from the interviews that what the students think or expect about the MPEX effort involved in learning physics does not match what they actually do.

DOI: 10.1103/PhysRevSTPER.7.010111

PACS numbers: 01.40.Fk

\section{INTRODUCTION}

Over the past decade, physics education research has indicated that student attitudes, beliefs, and assumptions about physics and learning physics play a critical role in how they learn and understand the subject $[1,2]$. In previous studies, physics education researchers have probed student expectations (distinguishing between the expectations of experts and the expectations of novices) and found relationships and positive correlations between student expectations and learning [3,4]. These indicated that student expectations in physics play a critical role in their learning and understanding. In this study, we focus on student cognitive expectations [5]—expectations about their understanding of the process of learning physics and the structure of physics knowledge which directly affect learning-rather than affective expectationexpectations about what they like and how they feel about learning physics which do not affect learning directly.

\footnotetext{
*scnem@mahidol.ac.th
}

Published by the American Physical Society under the terms of the Creative Commons Attribution 3.0 License. Further distribution of this work must maintain attribution to the author(s) and the published article's title, journal citation, and DOI.
Therefore, the word expectations used throughout this paper refers to cognitive expectations.

Studying expectations is important because they influence motivation [6] and affect the selection of learning strategies by students [7]. In particular, expectations affect students' ability to integrate their understanding of science concepts [8] and they also affect the ways that students evaluate their learning [9]. What students expect to happen in their introductory physics course plays a critical role in how they respond to the course. It affects what they listen to and what they ignore in the "fire hose" of information provided during a typical course by professor, teaching assistant, laboratory, and text. It affects which activities they select in constructing their own knowledge base and in building their own understanding of the course material $[2,5]$. Along with conceptual understanding and problem solving, physics education researchers began studying expectations through interview studies to develop a better appreciation of how students thought about these issues. Lin interviewed 25 students who were doing poorly in a university calculus-based physics course in 1982 [1]. He interviewed students about many topics, such as how they approached problem solving, how they studied from textbooks, and what their attitude were toward the physics course. The results showed that students' answers to every 
topic differed from the physics teachers' views, and many of the student difficulties were related to their attitudes about learning and the nature of what they learned in a physics course.

Another case study used interviews and tape-recorded observations to study two students' conceptions, understanding, and performance. This research was completed by Hammer in 1989 [2]. He met each student separately five times over the semester. Each meeting took about an hour and involved various tasks: open-ended discussions on the student's impressions, specific concepts, a midterm exam, problem solving, and so on. Hammer found that the way the class was taught reinforced student cognitive expectations and resulted in a good grade but did not promote learning physics with understanding. Both students in his study were able to earn good grades by emphasizing rote memorization. In addition, he found that general misconceptions of what physics is and how to approach it caused student difficulties in learning the subject.

In a similar way to studies of alternative conceptions of physics and physics problem solving, studies on student expectations show discrepancies between expert expectations (what instructors want students to believe about what physics is and how best to learn it) and novice expectations (what students believe about what physics is and how best for them to learn it). In general, experts think about physics like physicists. They see physics as being based on a coherent framework of concepts that describe nature. On the other hand, novices see physics as being based on isolated pieces of information that are handed down by an authority [5,10] (e.g., book or instructor) and have no relationship with their everyday lives.

Since the construction of expectation surveys, there have been a number of studies of student expectations showing that correlations between student's expectations and his or her learning do exist. Perkins et al. [11] found positive correlations between particular student beliefs and conceptual learning gains. By using the Colorado Learning Attitudes about Science Survey (CLASS) [10] and the Force and Motion Conceptual Evaluation (FMCE) [12], they found that student beliefs in the categories conceptual understanding and math physics connection had positive correlations with learning gains that were statistically different from zero. Kortemeyer [13] also found a positive correlation between student expectations and conceptual learning using the Maryland Physics Expectations (MPEX) [5] and the Force Concept Inventory (FCI) [14]. This is consistent with the work of Coletta and Phillips [15] who observed a strong correlation between the FCI gain and the MPEX score. Although significant correlations were found between the overall MPEX and some of the MPEX clusters with learning gains, significant correlations between the effort cluster and learning gains were not often seen. The effort cluster deals with how students are expected to think carefully and evaluate what they are doing based on available materials and feedback [5]. Kortemeyer [13] found no significant correlations between student expectations in the MPEX effort cluster and their conceptual learning using FCI. Dancy [16] also detected no significant correlations between student expectations in the effort cluster and their performance on homework, tests, and the final exams. The same results occurred when using CLASS to probe student expectations. Perkins et al. [11] also discovered no discernible correlations between the sense making or effort cluster and conceptual learning. Even in the original paper on MPEX, Redish et al. [5] mentioned that student responses to the effort cluster might not match what they actually did. Therefore, we wonder what the student expectations in the effort cluster are actually telling us.

It might be deduced from the previous studies $[11,13,15,16]$ that students' responses in the effort cluster are not very important to their learning, as measured by the FCI or FMCE. Consequently, it would be interesting to answer the following research questions.

(1) Do student expectations in the effort cluster have any correlation with student conceptual learning gains?

(2) If this is true, does the effort cluster have a significant correlation with student learning as measured by problemsolving questions?

(3) Would students from a different cultural environment (university students in Thailand) show correlations between MPEX scores and measures of student learning comparable to the results of published studies of American university students?

In this study, we conducted a survey to find answers to these questions. It should be noted here that our research work has been carried out in a Thai cultural environment which is different from other studies published in the physics education research (PER) literature $[5,11,13]$. In Thailand, physics is known as a very difficult subject for students and, as a result, it does not interest most of them. Many students only take physics courses because it is one of the subjects required in the university entrance examination [17]. Most of them focus on passing the course and learning by memorization rather than understanding the physics concept. Thai students tend to be shy and have a high respect for their instructors and professors. During classes, they are generally sitting, listening, taking notes, and rarely asking questions. This may be taken to represent the difference between student cultures in Thailand and those in other countries.

In our investigation, we used MPEX to probe first-year undergraduate science students' expectations, we used FMCE to evaluate student conceptual learning, and used final exam scores to evaluate student problem-solving ability. In addition, we also interviewed a group of students to find out more about how they learned in reality and compared this with their responses to the effort cluster. 


\section{A. MPEX and CLASS}

One of the first and best known student expectation surveys was the Maryland Physics Expectations survey developed by Redish et al. [5,18]. In it, attention is focused on students' expectations of how they understand the process of studying physics, the nature of physics, and what they have to do to succeed in their courses. The survey comprises 34 items. Students taking the MPEX survey are asked to rate their agreement with each item using a fiveoption Likert scale, that ranges from strongly disagree to strongly agree. In the work of Redish et al. [5], student responses were divided into 3 groups - strongly disagree or disagree as the first group, neutral as the second group, and agree or strongly agree as the third group. After that, they were categorized as either favorable or unfavorable, as determined by the most common responses from an expert group. Responses agreeing with the experts were defined as favorable and the responses disagreeing with the experts were defined as unfavorable. The expert view was that commonly selected by physics faculty who were committed to implementing PER-based curricula, as described in Redish et al. [5]. Alternatively, one might just call this the favorable view rather than the expert view.

Following the above, the percentages of student favorable and unfavorable responses in each item were grouped into 6 "clusters" [5].

(1) Independence-beliefs about learning physicswhether it means receiving information only or involves an active process of reconstructing one's own understanding.

(2) Coherence-beliefs about the structure of physics knowledge - a collection of isolated pieces or as a single coherent system.

(3) Concepts-beliefs about the content of physics knowledge- formulas, or as concepts that underlie the formulas.

(4) Reality link-beliefs about the connection between physics and reality - whether physics is unrelated to experiences outside the classroom or whether it is useful to think about them together;

(5) Math link-beliefs about the role of mathematics in learning physics - whether the mathematical formalism is used just to calculate numbers or is used as a way of representing information about physical phenomena; and

(6) Effort — beliefs about the kind of activities and work necessary to make sense out of physics-whether they expect to think carefully and evaluate what they are doing based on available materials and feedback or not.

Another popular survey is the Colorado Learning Attitude about Science Survey constructed by Adams et al. [10] at the University of Colorado. The CLASS is a new instrument designed to measure student beliefs about physics and learning physics and to distinguish the beliefs of experts from those of novices. The survey contains 42 items that ask students to rate their agreement. This
TABLE I. Categories in MPEX and CLASS surveys.

\begin{tabular}{ll}
\hline \hline MPEX & \multicolumn{1}{c}{ CLASS } \\
\hline Independence & Conceptual understanding \\
Coherence & \\
Concept & \\
Reality link & Real world connection \\
Math link & Math physics connection \\
Effort & Sense making or effort \\
& Personal interest \\
\hline \hline
\end{tabular}

instrument extends previous work by probing additional aspects of student beliefs and by using wording suitable for students in a wide variety of physics courses. As initial starting points for the CLASS statements, many MPEX items were modified in order to make the statements as clear and concise as possible. A number of new statements were also created to address certain aspects of learning not covered by the earlier surveys such as personal interest, aspects of problem solving, and the coupled beliefs of sense making and effort.

We explored all categories of the MPEX and CLASS to see the similarities and differences between them, based on the work of Redish et al. [5] and Perkins et al. [11], who categorized the MPEX and CLASS items into clusters as shown in Table I.

The independence, coherence and concept clusters in MPEX are equivalent to the conceptual understanding cluster in CLASS. Also, reality link is equivalent to real world connection, math link is equivalent to math physics connection, and effort is equivalent to sense making or effort. Additionally, CLASS has the extra personal interest category as mentioned above.

\section{B. Effort cluster in the MPEX}

Normally, physics instructors expect their students to take good notes during lecture class and then go over them carefully afterwards. Most instructors do not expect their students to follow everything during the lecture. Unfortunately, many students do not take good notes and rarely look at them. With more difficult physics content, most instructors expect students to try to figure things out using a variety of techniques to make sense of the material. Common techniques are working through the examples in the book, trying additional problems, talking to friends and colleagues, and so on. These are steps they can take that will eventually help them make sense of the topic. On the other hand, when things get too difficult, some students may get lost about what to do. Making the effort to go over the book and class activities helps students build their own understanding. Moreover, mistakes students make in their homework and in exams can give them guidance and help them to correct their misunderstanding. All of the effort items in the MPEX survey, with their associated number, are shown below [5]: 
No. 3: I go over my class notes carefully to prepare for tests in this course.

No 6: I spend a lot of time figuring out and understanding at least some of the derivations or proofs given either in class or in the text.

No. 7: I read the text in detail and work through many of the examples given there.

No. 24: The results of an exam don't give me any useful guidance to improve my understanding of the course material. All the learning associated with an exam is in the studying I do before it takes place.

No. 31: I use the mistakes I make on homework and on exam problems as clues to what I need to do to understand the material better.

Items 3, 6, and 7 describe activities beyond doing the homework that help students develop a good understanding of the material. Experts expect that good students will agree with these items. Items 24 and 31 ask if students make the effort to use the graded exams and homework as feedback to debug their understanding of physics or problem-solving methods. The favorable view is that good students will disagree with item 24 and agree with item 31 [19].

\section{METHODOLOGY}

Introductory physics is a course for first-year students at many universities in Thailand. Generally, the introductory physics classroom setting is a large hall with seating for more than 200. This is also the setup used for this study. An introductory calculus-based physics course was designed for first-year science students whose major subject was not chosen until the second year of study. The goal of this course was that students should be able to understand, explain, and apply the basic laws and concepts of mechanics, thermodynamics, wave, and optics after completion of the course in the first semester. The 15 week course consists of three hours of lectures per week, separated into one two-hour lecture and one one-hour lecture. There are no laboratories and recitations included (physics laboratories are registered as a separate course), and lecturing is the teaching style in this course. Both the teaching of concepts and problem-solving sessions are combined together into the lecture hours. Supportive team teaching was used, with two lecturers being in the classroom at the same time [20]. The two lecturers have their own roles during the lectures: one explains and the other one writes down the concepts on transparencies and also gives further important information. In class, students were supplied with guided worksheets [21]. The worksheets were carefully designed to enhance interactive learning between the lecturers and students. Both conceptual questions and problem-solving activities were embedded within the worksheets [22]. Necessary concepts were provided and there were some blank spaces, missing information, to enable the students to think and follow up. Sometimes the worksheets were distributed to accompany an activity or demonstration in the lecture. Students were asked to observe and write down what they saw in the blank spaces on the worksheet. They were also used to reinforce the concepts that the lecturers were about to explain. The lecturers would describe the main concepts and simultaneously write down the information in the blank spaces for the students to follow. When it came to a problem-solving item on the worksheets, the lecturers would let the students think by themselves, discuss with their neighbors, and work through that problem. Occasionally, the lecturers would ask questions. At the end, the lecturers would show the whole class how to solve the problem. Students were encouraged not to delete their own working for the solution but to copy the lecturers' solution next to it so they could compare the two. The lecturers consequently provided similar problems for the students to solve after class as homework in order to review and strengthen their understanding. Students were given credit for their homework and class attendance, and their grades were awarded based on these credits together with the midterm and final exams. After the midterm examination, the marked exam papers were given to the students so that they could check their score, learn how well they did, and discuss the mistakes they made with the instructors. In addition, the students were provided with a textbook written by the lecturers as well as other suggested textbooks available in the library.

The 212 and 199 first-year science students in the introductory physics course at a leading Thai university were probed using the MPEX survey during the first semester of the academic years 2007 and 2008, respectively. The 2007 and 2008 classes were conducted using the same instructional style as described previously and taught by the same instructors. Since the MPEX survey was specifically designed for a calculus-based introductory physics course and the authors were also familiar with its original version, this surveying method was chosen for the present study. The students took approximately $20 \mathrm{~min}$ of the first hour of the course to complete the survey. The expectation analysis was done in the same way as in Redish et al. [5] and Redish [23]. In order to evaluate student conceptual learning, the FMCE [12] was also administered to the students as a pretest and a post-test-a conceptual test developed to probe students' understanding of force and motion.

Since English is not the native language of Thai people, instruction was given in Thai and a translation was needed for the MPEX and FMCE. For the FMCE, the translation was carefully performed by an experienced Thai physics professor who has done many translations of English physics problems into Thai [24]. The Thai version of the test uses technical terms that are understandable by first-year students. Each question was translated in a way that all its original meanings were kept and no further explanations were given. The translation into Thai was validated by 20 academic staff and graduate students in the physics 
department at Mahidol University. They were asked to do both Thai and English versions of the test. The Thai test was given first and then the English test. Therefore, the staff and students had no chance to translate the test on their own. With minor adjustment of the translation, all of the staff and students arrived at the same answers for each question in both the Thai and English tests. The translation of the MPEX survey was performed in a similar way.

The final examination was also used to probe the students' problem-solving ability. The examination contained open-ended questions in both explanation and calculation formats. The final exam used in this study was in the same format as those used for the past seven years [22]. Some $80 \%$ of the exam is in calculation format, asking students to solve several physics problems related to the taught contents, while the other $20 \%$ is in explanation format asking students to give reasons, draw pictures, or explain their ideas without calculation. Subsequently, the overall final exam scores were recorded. Correlations between individual student expectations (precourse MPEX scores) and their learning [normalized FMCE gains $(\langle g\rangle)[25,26]$ and final exam scores] were studied using Pearson-r correlation.

Although the MPEX survey is a very useful and appropriate method to be implemented in a large class, and was designed for probing student expectations in learning physics, student interviews are still required in order to elicit details more deeply. Therefore, unstructured interviews were conducted with some students to gain more insights into their expectations. The major goal of these interviews was to validate the student effort expectations by listening to the interviewees' interpretations of the survey items and their explanations of why they answered them in the way they did. These interviews also helped to highlight the strategies and techniques the students used to understand physics as well as the aspects they felt aided or hindered their learning. The students who were interviewed were selected based on their favorable score in the effort cluster of the MPEX survey, which was given at the beginning of the semester. The interview subjects fell into one of two groups: students with extremely low favorable scores in the precourse MPEX effort cluster (0\% FAV) and students with extremely high favorable scores on the precourse MPEX effort cluster (100\% FAV). The interview questions focused on the students' efforts in learning physics, on tasks corresponding to the effort items on the MPEX survey. These interviews were conducted at the end of the semester before the final examination. The subject students were interviewed singly and before answering the interview questions. Each student was asked to go over the effort items, depending on the available time for that particular interview. They were asked to interpret and complete only the effort items in the MPEX survey and to explain their reasons for supporting their responses in order to ensure that they understood the items correctly. The interviewer used the following questions based on the effort items as well as additional and appropriate followup questions.

Question 1: "How did you prepare yourself for the physics exam?"

Question 2: "Do you think that the results of the exam give any useful guidance to improve your understanding of the course material?"

Question 3: "Do you think the mistakes you make on homework or in the exam help you in any ways?"

Each interview took approximately 15-20 min to complete. All the interviews were audio taped and then transcribed. Two researchers were used to achieve acceptable accuracy in the transcripts. One performed the transcription and the other checked the consistency between the interview audio tapes and transcripts. The interview transcripts were analyzed to see if there were any differences between the efforts of these two student groups and also to see whether the effort measured by the MPEX survey was consistent with the efforts they really displayed during the physics class.

\section{RESULTS}

\section{A. Student expectations and learning}

Table II shows details of average scores and standard deviations of students' precourse MPEX favorable, preFMCE, post-FMCE, normalized FMCE gains, and final exam scores in the years 2007 and 2008. Between these academic years, there is no statistically significant difference in precourse overall MPEX favorable scores and their normalized FMCE gains (using an independent-samples t-test). There is statistically significant difference between

TABLE II. Average scores and standard deviation (SD) of MPEX favorable, FMCE, and final exam scores in the years 2007 and 2008.

\begin{tabular}{lrrrr}
\hline \hline & \multicolumn{2}{c}{$2007(n=212)$} & \multicolumn{2}{c}{$2008(n=199)$} \\
& Mean & \multicolumn{1}{c}{ SD } & Mean & SD \\
\hline Precourse overall MPEX (\% FAV) & 43.02 & 14.43 & 45.36 & 16.55 \\
Pre-FMCE (43 points) & 15.73 & 9.03 & 13.64 & 8.36 \\
Post-FMCE (43 points) & 22.09 & 10.52 & 21.53 & 10.17 \\
Normalized FMCE gains & 0.26 & 0.02 & 0.29 & 0.02 \\
Final exam score (90 points) & 52.36 & 16.28 & 42.85 & 16.12 \\
\hline \hline
\end{tabular}


TABLE III. Pearson-r correlation coefficients between students' percentages of favorable responses (precourse MPEX scores) and learning.

\begin{tabular}{|c|c|c|c|c|}
\hline \multirow[b]{3}{*}{ Expectation Clusters } & \multicolumn{4}{|c|}{ Correlations of percentages of favorable responses with } \\
\hline & \multicolumn{2}{|c|}{2007} & \multicolumn{2}{|c|}{2008} \\
\hline & $\begin{array}{l}\text { Normalized FMCE gain } \\
\text { ( } p \text { value })\end{array}$ & $\begin{array}{l}\text { Final exam score } \\
\qquad(p \text { value })\end{array}$ & $\begin{array}{l}\text { Normalized FMCE gain } \\
\qquad(p \text { value })\end{array}$ & $\begin{array}{l}\text { Final exam score } \\
\qquad(p \text { value })\end{array}$ \\
\hline Overall & $0.310(0.000)$ & $0.343(0.000)$ & $0.229(0.001)$ & $0.349(0.000)$ \\
\hline Independence & $0.241(0.000)$ & $0.237(0.001)$ & $0.213(0.002)$ & $0.283(0.000)$ \\
\hline Coherence & $0.282(0.000)$ & $0.295(0.000)$ & $0.022(0.757)^{\mathrm{a}}$ & $0.179(0.011)$ \\
\hline Concept & $0.242(0.000)$ & $0.222(0.001)$ & $0.152(0.032)$ & $0.342(0.000)$ \\
\hline Reality link & $0.232(0.001)$ & $0.260(0.000)$ & $0.144(0.043)$ & $0.182(0.010)$ \\
\hline Math link & $0.267(0.000)$ & $0.276(0.000)$ & $0.188(0.008)$ & $0.232(0.001)$ \\
\hline Effort & $-0.060(0.385)^{\mathrm{a}}$ & $-0.066(0.340)^{\mathrm{a}}$ & $0.109(0.127)^{\mathrm{a}}$ & $0.145(0.040)$ \\
\hline
\end{tabular}

${ }^{\mathrm{a}}$ Not significant in two-tailed $(p>0.05)$.

the students' pre-FMCE scores but it is small. From these results, it appears that before the class the students' incoming favorable expectations and their conceptual understanding about force and motion for both years were quite similar. Both years' post-FMCE scores are also fairly close. However, although the instruction given to both groups of students was the same, the average final exam score in the year 2007 was significantly higher than in the year 2008 .

In Table III, we show the Pearson-r correlation coefficients between individual student expectations (precourse MPEX scores) and their conceptual normalized gains (normalized FMCE gains).

The expectations were divided into 6 clusters as discussed previously. We were interested in the students who completed both the precourse MPEX and the pre- and postFMCE $(N=212$ and $N=199$ for academic years 2007 and 2008, respectively). For the 2007 students, the correlations of the overall MPEX score and five of the cluster scores with the normalized FMCE gain were statistically significant and ranged from 0.232 to 0.310 , while the correlation with the effort cluster was -0.060 and not significant in a two-tailed t-test. From these results, we tried to ascertain whether student expectations in the effort cluster correlated with other measures of learning or not. We then correlated student expectations with their overall final exam score which came from the whole of the final test. The results showed that the correlation coefficients range from 0.222 to 0.343 for the overall MPEX score and five of six MPEX cluster scores. Student expectations in the effort cluster again showed no statistically significant correlation with the final exam score.

For the year 2008, the statistically significant correlations ranged from 0.144 to 0.229 for the normalized FMCE gains with the overall MPEX score and four of the cluster scores. The correlation with the effort cluster was 0.109 and not significant. For the correlations with the final exam score, the statistically significant coefficients ranged from 0.145 to 0.349 . The results present a small positive correlation ( 0.145$)$ between student effort expectations and their final exam score.

These results are consistent with the work of Kortemeyer [13] and Dancy [16]. Kortemeyer found a small positive correlation of 0.01 between the MPEX effort cluster and the final exam scores in his study, whereas Dancy found no significant correlation between the MPEX effort cluster and the final exam scores. Both Dancy and Kortemeyer did, however, find significant correlations (Dancy 0.24-0.39 and Kortemeyer 0.25-0.36) between the MPEX independence, coherence and concept clusters with the final exam scores.

Because of the low correlations between student effort expectations and their learning, it seems that students who came to class with more favorable expectations in the effort cluster were not likely to achieve high learning gains. So what are the student expectations in the effort cluster really telling us? In order to gain further information beyond these student effort responses, the student interviews can be seen as an extremely useful tool.

\section{B. Student interviews}

We interviewed two groups of five students each with different results in the precourse MPEX score and the normalized FMCE gain $(\langle g\rangle)$. One group had extremely unfavorable precourse MPEX effort cluster scores and one group had highly favorable precourse MPEX effort cluster scores. The following subsections show details of the students' answers including the reasons for supporting their effort item responses as well as the answers to the interview questions themselves.

\section{Group of students with high favorable responses in the precourse effort cluster}

In the interview about student effort performed during the physics course under study, we asked five students who had high favorable responses $(100 \%$ agreeing with the experts) in the precourse effort cluster to complete only 
the effort items in the MPEX survey and explain the reasons for their responses. We also asked all the three interview questions to each student in this group. Some of them had high learning outcomes but others did not. Details of the student performances on the course are presented in Table IV. This table shows various levels of performance. Even though they had the same highly favorable precourse effort scores, the students' normalized learning gains and final exam scores ranged from poor to excellent.

All the student responses to the effort items during the interviews are presented in Table V. Most of the student responses to the effort items are still favorable responses compared to their precourse effort responses, especially for students no. 2 and 5. Although some discrepancies between the precourse expectations and during the interviews were found, they had changed their view to be neutral (students no. 1, 3, and 4). No students changed their view to be unfavorable.

In the paragraph below the student reasons for their effort item responses during the interviews are shown.

Student no. 1 changed a response to effort item 6 from favorable to neutral and gave the following supporting reason.

"I did not spend too much time with that. I focused more on working through problems because it helped me understand more."

Although the student response to item 6 is classified as neutral, an unfavorable view is embedded within the reason. The student did not spend much time figuring out derivations or proofs but focused more on solving problems.

Student no. 2, who had a very low normalized FMCE gain, still gave all favorable views on the effort items, which was the same as at the beginning of the class. After asking the student to provide some explanations for the responses, we found the following reason for item 6 .

"Personally, I don't like figuring out the derivations or proofs for a long time but I think we have to spend some time with them in order to understand the contents."

This reason reveals that the given favorable response is what the student thinks they should do to understand physics content rather than what they would prefer to do.
TABLE V. Effort item responses during the interviews of the students with high favorable precourse effort expectations: favorable $(\mathrm{F})$, neutral $(\mathrm{N})$, and unfavorable $(\mathrm{U})$

\begin{tabular}{lccccc}
\hline \hline & \multicolumn{5}{c}{ Item responses } \\
Student & No. 3 & No. 6 & No. 7 & No. 24 & No. 31 \\
\hline No. 1 & F & N & F & F & F \\
No. 2 & F & F & F & F & F \\
No. 3 & F & F & N & F & F \\
No. 4 & F & N & N & F & F \\
No. 5 & F & F & F & F & F \\
\hline \hline
\end{tabular}

Student no. 3 started the class with a $100 \%$ favorable view on all the effort items and then changed the view to be neutral on item 7. However, the given reason shows that the student still had a favorable view on this item.

"I tried to read and work through the examples but there were also many things to do in other subjects. So, I could not do it as much as I had intended."

This student tried to read and work through physics examples, which is considered a favorable view. However, because of time limitation and work load in other subjects, the student could not do it as much as expected. As a result, student no. 3 gave a neutral response. This illustrates a difference in the ways students no. 2 and 3 approached the survey. Student no. 2 talked about what they thought they should do, while student no. 3 tried to talk about the things they actually did in class.

Student no. 4 changed to give a neutral view for effort items 6 and 7. The student gave the following reason to support the response to item 6 .

"Because some of the topics are difficult and some are easy."

This could mean that in some topics the student spent less time to figure out derivations or the proofs but some other topics need much more time, depending on their level of difficulty. This should be considered a favorable view, as the student pays attention to at least some of the derivations or proofs.

For item 7, the student reason is "Because I have not got enough time to do that."

TABLE IV. Performances of students with high favorable precourse effort expectations.

\begin{tabular}{lccccc}
\hline \hline Students & & & & $\begin{array}{c}\text { Precourse MPEX } \\
\text { favorable percentages } \\
\text { (overall) }\end{array}$ \\
\hline No. 1 & (43 points) & $\begin{array}{c}\text { Post-FMCE } \\
\text { (43 points) }\end{array}$ & $\begin{array}{c}\text { Normalized } \\
\text { FMCE gains }\langle g\rangle\end{array}$ & $\begin{array}{c}\text { Final exam score } \\
\text { (90 points) }\end{array}$ & 55.88 \\
No. 2 & 11 & 11 & 0.00 & 49.5 & 61.76 \\
No. 3 & 11 & 14 & 0.09 & 36.0 & 67.65 \\
No. 4 & 18 & 40 & 0.88 & 80.5 & 73.53 \\
No. 5 & 32 & 39 & 0.64 & 89.0 & 94.12 \\
\hline \hline
\end{tabular}


It seems that the student would like to figure out derivations or proofs, and this is considered as a favorable view. However, the student did not have enough time to do these things. This is the same for student no. 3-the students tried to answer what they actually did in the class.

Student no. 5 retained all of the favorable responses, and all of the supplied reasons also represented favorable views.

According to the student responses and their associated reasons for the MPEX effort items, there is considerable support for the idea that what students think or expect differs from what they actually do. There were favorable and unfavorable views found behind the neutral responses. The students knew what useful things they should do, but they could not actually perform them in class. This fact causes some discrepancies between the precourse and postcourse MPEX responses. The students tried to answer about the exact things they did (after class response) instead of the things they should do or wanted to do (before class response).

To obtain more in-depth information about the student views and the ways they learned, we asked all the three interview questions to this student group. Details of the students' answers to the interview questions are shown in the following.

Answers to question 1. The favorable view on the effort expectation item is that students will go over their class notes carefully, read the text in detail and work through the many examples given to prepare for the course tests. Although all of the students in this interview group agreed with the experts, they still had their own alternative ways of preparing themselves for the physics exam. Below are some student responses to interview question 1.

"I think working through many physics problems could help." (student no. 1)

"I did not focus on reading the theory. What I did was solving more physics problems. I tried to find various types of them." (student no. 2)

"Mostly, I did not read through the text or the notes. I just focused on the summaries and looked at only important formulas. I think I learn from solving physics problems." (student no. 4)

These statements reveal that the students' attention seems to be solely focusing on solving various physics problems in preparing themselves for the tests. They are probably not intending to go carefully over their class notes or problems and figure them out or read the text in detail. The activities described in these quotes are not consistent with what instructors would expect from students with such high favorable responses on the MPEX effort cluster. The quotes from students no. 1, 2, and 4 are consistent with what one would expect from students with unfavorable expectations.

Taking good notes during lectures, figuring them out carefully, and then reviewing them to prepare for exams are examples of favorable effort activities. The quotes shown below from students no. 3 and 5 are more what would be expected from students with highly favorable effort cluster scores. These quotes are excellent examples of student responses consistent with a favorable response to MPEX item 3.

"We need to understand first. Understand the core concepts and where the formulas come from by reading class worksheets and my own notes. Then I try to summarize from the textbook. I also focused on the given examples." (student no. 3)

"Besides reading the class worksheets, I will read textbooks for unclear points. I think it explains things clearly. I pay more attention to the contents first and then work through physics problems only for the more difficult and interesting ones." (student no. 5)

Because worksheets had been distributed during this course, most students jotted the notes down on these instead of in separate notebooks. The students then reviewed these worksheets before the physics exam. The above statement by student no. 5 explicitly indicates that the student tried to read the notes in detail and make sense of the material by reading additional textbooks. This is an activity that experts would expect from students with favorable effort expectations to help themselves understand the topic.

The student quotes presented above show that while two of the students with favorable effort scores appeared to use their notes to help them prepare for tests, an activity consistent with a favorable effort response to MPEX item 3, the other three did not. Instead these three students focused on more problem-solving practice or at most only looking at the "important" equations.

Answers to question 2. All of the following statements reveal in various ways that the students think that the results of an exam would give useful guidance to improve their understanding of the course material.

"We need to review and read more." (student no. 1)

"It shows that we need to prepare ourselves better because we don't know for sure what's going to be in the exam. The exam is flexible. So, we need to prepare and do our best." (student no. 2)

"What is taught in the class and what is in the exam are not always the same. The tests are to examine our understanding and the test questions can be different. We need to be able to adapt our knowledge and understanding to the problems. So the scores represent how much we understand and how we should improve ourselves." (student no. 3)

"The exam results are useful guidance to improve our understanding." (student no. 4)

"The exam results showed how much we could do when facing the real situation." (student no. 5)

The quotes are all what we would expect from this group of students. They are consistent with favorable responses to 
MPEX item 24. That is, students should make an effort to use the exam results as feedback to reevaluate their understanding.

Answers to question 3. This interview question is consistent with MPEX effort item 31. Most instructors expect that the mistakes students make in homework and in exams can give guidance to help them correct their errors. After finding some mistakes, students could try to figure them out using various techniques to make sense of them, such as reading additional textbooks, asking the lecturers, talking to friends or colleagues, and so on.

The following student views indicate whether or not they think that the mistakes they made in homework or exam problems are helpful in improving their understanding of the course material.

"The mistakes that we make show what we do not understand and if we review them again, it might help us remember more." (student no. 1)

"Yes, I will remember. Remember what I used to do wrong." (student no. 4)

The above statements suggest that the two students learn by rote from the errors they made in homework or exams. They paid more attention to the mistakes and remembering them instead of performing a critical review and rechecking their understanding. These, however, were not activities we expected from students with high favorable effort responses.

Other responses showed that mistakes also helped some of the students to improve their own understanding. These responses are

"If I can, I will try to clear and correct the mistakes. Even though the mistakes are terrible, we need to accept that." (student no. 2)

This student presents his favorable view on using mistakes to correct his understanding. However, the words "If I can" lead us to thinking that the student might not always do such a thing. Although he seemed to realize that correcting the mistakes he made in homework or the exam was helpful, it is not obvious that he would actually do it.

"The more we practice with the homework the more we see our faults. This helps us to be more careful." (student no. 3)

"It's like when the professors let us see the returned exam papers, we can check all the mistakes we made. So, we pay more attention to those points." (student no. 5)

These two students used their errors as clues or hints for improving their understanding of the course material. The mistakes they made were used as error experience. This is consistent with a favorable view in the effort cluster.

In summary, the responses of the five students to the MPEX survey demonstrated that, initially, all of them agreed with the experts in all of the effort items. However, they performed differently during the courses. This assertion is supported by their reasoning about their effort item responses and their answers to the three interview questions. Some of the activities they performed were below the level expected by experts, such as paying more attention to problem solving, ignoring the detailed reading of the course notes, spending no time on the derivations or proofs given either in the class or in textbooks, and learning by rote from their mistakes.

\section{Group of students with low favorable responses in the precourse effort cluster}

Additional insights into the thoughts the students have about their performances in the physics course can be found by asking some questions to those who had low favorable effort cluster scores. In these interviews, we asked five students who had low favorable responses (0\% agreeing with the experts) in the precourse effort cluster to complete only the effort items in the MPEX survey and explain the reasons for their responses. We then asked them the same three interview questions as above. It should be pointed out that all five students performed differently in the physics course. The details of their performances are presented in Table VI. Normally, this group should have low learning outcomes. However, high normalized conceptual learning gains and final exam scores also occurred for them.

The student responses to the effort items during the interviews showed discrepancies in their expectations as presented in Table VII. Some of the students changed their views to be favorable.

Student no. 6, who had a low conceptual learning gain, gave one different view in effort item 3 during the interview. The reason is shown below and it supports the student's changed view.

"I am not good at physics. Thus, I have to review it often."

Student no. 7 gave different views on items 6 and 31 . The student started to pay more attention to the derivations and proofs. Here is the reason the student gave for item 6.:

"Knowing where formulas come from or how to derive them helps me understand the contents more. I don't have to remember too many formulas."

Although the student response to item 6 was favorable, the supplied reason was still related to memorization. For item 31 the supporting response was as follows:

"For some problems or given homework that we did not understand, we would understand more when the instructors showed us how to solve for the solution in the class."

The above reason reveals that this student understood the course material better when the instructors showed or gave some clues of how to solve problems during the classes. From this, the discrepancy in student's views before and after the course could be explained by the instructional style.

It is interesting that student no. 8, who had a zero conceptual learning gain, almost completely changed from unfavorable views to favorable views. However, the 
TABLE VI. Performances of students with low favorable precourse effort expectations.

\begin{tabular}{lccccc}
\hline \hline Pre-FMCE & $\begin{array}{c}\text { Post-FMCE } \\
\text { (43 points) }\end{array}$ & $\begin{array}{c}\text { Normalized } \\
\text { FMCE gains }\langle g\rangle\end{array}$ & $\begin{array}{c}\text { Final exam score } \\
\text { (90 points) }\end{array}$ & $\begin{array}{c}\text { Precourse MPEX } \\
\text { favorable percentages } \\
\text { (overall) }\end{array}$ \\
\hline No. 6 & 7 & 10 & 0.08 & 49.0 & 11.76 \\
No. 7 & 12 & 18 & 0.19 & 49.5 & 8.82 \\
No. 8 & 14 & 14 & 0.00 & 44.5 & 23.53 \\
No. 9 & 31 & 43 & 1.00 & 56.5 & 26.47 \\
No. 10 & 34 & 42 & 0.89 & 37.0 & 38.34 \\
\hline \hline
\end{tabular}

TABLE VII. Effort item responses during the interviews of the students with low favorable precourse effort expectations: favorable $(\mathrm{F})$, neutral $(\mathrm{N})$, and unfavorable $(\mathrm{U})$.

\begin{tabular}{lccccc}
\hline \hline & \multicolumn{5}{c}{ Item responses } \\
Students & No. 3 & No. 6 & No. 7 & No. 24 & No. 31 \\
\hline No. 6 & F & U & U & U & U \\
No. 7 & U & F & U & U & F \\
No. 8 & F & N & F & F & F \\
No. 9 & U & U & U & U & U \\
No. 10 & F & F & N & U & F \\
\hline \hline
\end{tabular}

student's reason for effort item 7 represents both a favorable and unfavorable views.

"Sometimes working with many examples may cause confusion but working through examples is a very good thing. It makes us familiar with those topics and so I don't need to read the text in detail."

The student's favorable view is shown when she mentioned that working through examples is a very good thing. However, when the student said working through many examples caused confusion and reading the course notes in detail is not required, the unfavorable view is also displayed. The student seems to answer what she thinks as well as what she really does.

It is also interesting that student no. 9, who had a very high conceptual learning gain, retained all unfavorable responses, as can be seen from Table VII.

Student no. 10, who had a high learning gain as well, changed some views to be neutral or favorable. The supplied reasons support these favorable responses to three of the effort items. The reasons for effort items 3 and 6 are

"We jotted down what we understood during the class as lecture notes. So, in preparation for the exam, we had to review these notes."

"Normally, I did that (figuring out and understanding at least some of the derivations or proofs) in the class. If I was really interested in some specific formulas, I'd investigate them further in the course notes. Some proofs took a very long time before I could understand them."

This shows that the student read the notes and spent a lot of time figuring out some of the proofs given in the class or in the course textbook.
Students in this group show some discrepancies between the responses they gave to the effort items at the precourse stage and the responses they gave to these items during their interviews. Many of their responses were changed to be favorable after the course. Some of these discrepancies were caused by the instructional style of the course. For example, on seeing the instructors work through solutions in the class, one of the students reversed their view to see the benefits of learning from the mistakes they made in the homework or exams. This is consistent with the work of Hammer [2]: student expectations can be influenced by class instructional style. However, there was a student response supporting the idea that what students think, or expect, differs from what they actually do. This was also found when we looked closely at the student answers to the three interview questions.

Answers to question 1. As we know, the favorable view on the effort cluster is that students will go over their class notes carefully, read the course textbook in detail, and work through many of the examples given there to prepare for tests and the exam. Although all of the students in this group did not agree with these items, as expressed directly in the precourse MPEX survey, they still provide some interview information revealing their favorable performances in the course. That is, there is a favorable effort embedded inside the unfavorable responses.

As mentioned before, most students jotted their notes down on the worksheets instead of in their notebooks. Therefore, some students paid more attention to these worksheets rather than the textbooks, figuring them out carefully and then reviewing them to prepare for the exams. The activity shown in the following quote from student no. 8 is what would be expected from a student with a highly favorable effort cluster score, instead of a quote from this student who has a low favorable score. This quote is consistent with a favorable response to MPEX item 3:

"Mostly I start by reading the class worksheets to try to understand the theory and definitions. Then I look at the formulas to see how they are derived so that I don't need to remember them all. After that, I go over the problems." (student no. 8) 
Student no. 9 also went over the worksheets but did not read the textbooks in detail. However, he focused on the proofs of the formulas.

"I read the class worksheets only and focused on the proofs of formulas." (student no. 9)

This is consistent with a favorable response to MPEX item 6, while the student response to this item was unfavorable in the precourse MPEX survey.

Other students paid more attention to problem solving first. Only when they had a problem with the physics would they try to make sense of them by reading the textbooks. These quotes are considered as unfavorable efforts:

"I tried to practice on the supplied homework problems. Then I would summarize the contents of the class worksheets and read through them just before the examination." (student no. 7)

"Mostly, I did not read. I just focused on solving the physics problems. When I got stuck with some of these problems, I would then consult the textbook." (student no. 10)

Another student's opinion showed that the student did not care how the formulas were derived but just looked for usable ones. The following is an excellent example of a student response with an unfavorable effort expectation:

"I looked for the formulas and didn't care where they came from." (student no. 6)

The quotes presented above show that two of the students with extremely unfavorable effort scores appeared to use their notes on their worksheets to prepare for tests and make sense of the physics in ways that are consistent with favorable effort responses to the MPEX items. The other three students clearly displayed unfavorable activities that are inconsistent with effort expectations.

Answers to question 2. In relation to the exam results, we went through student thinking about the benefit of these by asking them whether they made an effort to use the exam results as feedback to debug their understanding of physics or not. The quotes below show the responses the students gave to interview question.

"It seems that when we finished the exam, we won't be seeing those topics again in the next exam. Therefore, I only learn the current content when preparing for the next exam." (student no. 6)

"The exam results show how much we did from the knowledge and skills we had previously. So it doesn't relate to the improvement of our understanding after the exam." (student no. 7)

The above quotes obviously point to unfavorable views. The students think that the results of the exam do not help them in any way. Firstly, the content which was already in the exam will not be tested again in the future. Secondly, the exam results only tell them how much they understood before the test. Therefore, they feel that the exam results do not give them any clue for improving their understanding. The activities described in these quotes are consistent with unfavorable responses on the MPEX effort cluster. In addition, student no. 6 seemed to learn physics by rote memorization, without making sense of content, and student no. 7 did not see any benefit of the exam results.

Nonetheless, favorable views also came out of this student group. The following quotes reveal that the exam results gave some of the students a clue for improving their understanding. The results showed them which topics they needed to concentrate on to improve their comprehension. The quotes below are consistent with a favorable response to MPEX item 24.

"Sometimes the exam is more difficult than what we worked on in class. So it gives us more knowledge than we learned during the course." (student no. 8)

"If we get low scores, we will pay more attention and learn more." (student no. 9)

"The exam results are one of the learning stimulators but they are not necessary if we are already focused on studying. However, they let us know which topics we were able to do." (student no. 10)

It can be seen that three of the five students with unfavorable effort scores understand that the exam results can give guidance in helping them to correct their errors and improve their understanding. These are then considered as favorable views which seem to be embedded inside unfavorable responses.

Answers to question 3. The students who gave unfavorable effort responses were asked to think if the mistakes they made in homework or exam problems were useful or not. Their answers are presented below.

"The mistakes in the exam and homework did not make me understand more about the course content because there was too much course material and examples." (student no. 6)

"Only some of the mistakes could help improve my understanding but other could not because I did not understand them before the exam as well." (student no. 9)

These statements confirm the students' unfavorable responses to MPEX item 31. The students do not agree that the mistakes they made might give them any clue for helping them to learn. While experts expect students to make an effort to use the errors they made in exams and in homework as feedback to debug their understanding of physics, these students did not think that the mistakes they made could help them understand more about the course material. One of the students thinks that some of the mistakes are useful but others are not.

Two of the other students appear to think that the mistakes they made are useful. Here are their quotes:

"The mistakes are probably useful. When I couldn't solve a problem, I copied the problem and then asked friends." (student no. 10)

"The mistakes are helpful. When we do the same kind of problems again, we will not repeat these mistakes." (student no. 7) 
The quote below is fairly consistent with the favorable view. It shows that there are some favorable efforts behind the unfavorable responses on the survey.

"Sometimes I go back to my mistakes. They let me know where I missed things and how I can improve." (student no. 8)

The last three quotes are more consistent with favorable views on the effort expectations. These students learned from their mistakes and made the effort to improve their learning.

In summary, the responses of this student group to the MPEX survey demonstrated that, initially, all of them disagreed with the experts in all of the effort items, but the results from the interview show that some of these students think they function in one fashion when actually they behave differently. Some of the students changed their views to be favorable because of the instructional style. Another group of these students disagreed with the favorable views and yet they still performed some favorable efforts.

\section{DISCUSSION}

We found that the overall favorable students' expectation score of students in two calculus-based introductory physics classes in Thailand had a significant correlation with student learning gains as measured by both conceptual and final exam tests. The results from two academic years show that five of the six MPEX categories correlate significantly with normalized FMCE gains and with final exam performance, except for the effort cluster. The results show no significant $(p>0.05)$ correlation between the favorable effort results and the student learning performance, as by normalized FMCE gain, for both the 2007 and 2008 classes, as well as no significant correlation with the final exam scores for the 2007 class. However, the 2008 class had a small positive correlation between their favorable effort results and their final exam scores. As with correlations in previous studies $[13,16]$, this one is so small that we cannot be sure if there really is a correlation. These results reveal the uncertainty of the correlations between student effort expectations and learning.

Because we conducted the survey at the beginning of the semester, it was expected that the students would respond to the effort cluster questions in terms of what they thought they should do. Thus it is not surprising that the effort cluster preresults do not correlate with student learning, as these will not reflect the effort that students would make to learn in their introductory physics course. Redish et al. [5] mentioned in their previous work that they saw a dramatic downward shift in student effort expectations at the end of the semester. The drop in the favorable percentages was approximately $10 \%-20 \%$. They suggested that the students might have expected to make more of an effort in the course than they actually did, which in turn might have caused the insignificant correlations found between student expectations in the effort cluster and learning. Perkins et al. [11] also reported that student postscores, as measured by CLASS, have stronger correlations with conceptual learning than the student prescores have.

To see if these also happened in our case, we carried out a MPEX survey on the students at the end of the 2007 semester. The student post reality link and effort favorable scores did not show much decline, as shown in Table VIII. The decrease in five out of the six MPEX clusters, i.e., except for the reality link cluster, was statistically significant using the Paired-Samples t-test. This is consistent with the finding of Redish et al. [5] that student expectations become less favorable over the course of a semester. Even in courses that are successful at improving student conceptual learning of physics, student expectations tend not to improve.

We also found weaker correlations between postcourse MPEX scores and normalized FMCE gains for almost all MPEX clusters as shown in Table IX. For the effort cluster, correlations of precourse and postcourse MPEX scores with the normalized FMCE gains are weak and not significant. Moreover, the effort to final exam score correlation becomes significantly negative, and while the overall and the other four MPEX cluster correlations increase with the final exam score, the reality link does not. This suggests that, for this study, the MPEX scores predict student problem-solving scores (final exam scores) better than they predict student conceptual learning gains, especially for the postcourse MPEX scores. This is somewhat different from the findings of Perkins et al. [11]. However, the effort cluster is still unable to predict both student conceptual learning gains and problem-solving scores.

From the interviews, we found that what many students actually did in their courses differed from how they responded to the MPEX effort items. Some unfavorable efforts were made by students who gave favorable responses on the MPEX effort cluster. On the other hand, some favorable efforts were often made by the students who provided unfavorable responses on the MPEX effort cluster. We also found that the instructional style had an effect on discrepancies in the student responses to the MPEX effort cluster. It seems that using worksheets during

TABLE VIII. Students' percentages of precourse and postcourse favorable MPEX scores in 2007.

\begin{tabular}{lcc}
\hline \hline Expectation cluster & \multicolumn{2}{c}{ Favorable MPEX scores } \\
Precourse & Postcourse \\
\hline Overall & 43.02 & 39.12 \\
Independence & 36.55 & 29.50 \\
Coherence & 33.69 & 25.08 \\
Concepts & 23.53 & 19.72 \\
Reality link & 52.34 & 51.77 \\
Math link & 28.28 & 22.43 \\
Effort & 57.60 & 54.33 \\
\hline \hline
\end{tabular}


TABLE IX. Pearson-r correlation coefficients between students' percentages of favorable responses (precourse and postcourse MPEX scores in 2007) and learning.

\begin{tabular}{lcccc}
\hline \hline & \multicolumn{2}{c}{$\begin{array}{c}\text { Correlations of percentages of favorable responses with } \\
\text { Precourse } \\
\text { Postcourse }\end{array}$} \\
Expectation clusters & $\begin{array}{c}\text { Normalized FMCE gain } \\
(p \text { value })\end{array}$ & $\begin{array}{c}\text { Final exam score } \\
(p \text { value })\end{array}$ & $\begin{array}{c}\text { Normalized FMCE gain } \\
(p \text { value })\end{array}$ & $\begin{array}{c}\text { Final exam score } \\
(p \text { value })\end{array}$ \\
\hline Overall & $0.310(0.000)$ & $0.343(0.000)$ & $0.261(0.000)$ & $0.378(0.000)$ \\
Independence & $0.241(0.000)$ & $0.237(0.001)$ & $0.238(0.001)$ & $0.339(0.000)$ \\
Coherence & $0.282(0.000)$ & $0.295(0.000)$ & $0.241(0.001)$ & $0.366(0.000)$ \\
Concepts & $0.242(0.000)$ & $0.222(0.001)$ & $0.274(0.000)$ & $0.277(0.000)$ \\
Reality link & $0.232(0.001)$ & $0.260(0.000)$ & $0.210(0.003)$ & $0.185(0.009)$ \\
Math link & $0.267(0.000)$ & $0.276(0.000)$ & $0.266(0.000)$ & $0.469(0.000)$ \\
Effort & $-0.060(0.385)^{\mathrm{a}}$ & $-0.066(0.340)^{\mathrm{a}}$ & $-0.043(0.547)^{\mathrm{a}}$ & $-1.44(0.043)$ \\
\hline \hline
\end{tabular}

${ }^{a}$ Not significant in two-tailed $(p>0.05)$.

the class helped the students jot down notes which they could then review before the exams. Going through derivations or proofs as well as showing how to solve some problems in class can also help students understand the course material better. In addition, giving back marked exam papers to the students allows them to see the mistakes they made and helps them learn the subject better. However, not all students saw these as useful activities in learning physics and, moreover, some of them agreed with these activities but they behaved differently. These above facts might account for the insignificant correlations between student expectations in the effort cluster and learning. Sometimes, it is seen that the effort expectations were just activities and work that students thought they should do to succeed in learning physics. The interesting thing is that the effort cluster questions are based on activities that instructors would like their students to do. Students also recognize these as things they or good students should do, even when they are not actually doing them. Thus, students' favorable MPEX effort responses are more likely to reflect what students think they should do rather than what they will actually do. According to these results, student expectations in the effort cluster, as measured by the precourse MPEX survey, do not appear to be able to predict what learning outcome the students will achieve. In that case, when using favorable MPEX scores to predict student learning outcomes, should the effort cluster be included in the overall MPEX scores?
In Table X, we compare the correlations of students' favorable MPEX scores and their learning. We are trying to see comparable correlations between using overall MPEX scores and those with the exclusion of the effort cluster. We see that excluding the effort items from the overall MPEX scores gives stronger correlations between the student expectations and their learning. This means that excluding the effort cluster might make the MPEX instrument become more effective in terms of predicting student learning outcome. The results here support the idea that the effort cluster does not accurately measure relevant student effort that correlates with student learning. The effort cluster does not reflect the effort that students are actually making in introductory physics courses. Redish [5] mentioned in the previous work that student responses to the effort cluster might not match what they actually did. This finding is supported by the student responses to the interview questions in this study.

From the results of this study, we can answer the three research questions. First, since the correlations we found were not statistically significant, this suggests that student expectations in the effort cluster are not correlated with student conceptual learning gains. Second, we see no significant correlation between student effort and final exam scores for the 2007 class and a small (of order $0.10)$, barely significant correlation $(p<0.05)$ for the 2008 class. Third, we found consistency between the correlation results obtained here in Thailand and the results of

TABLE X. Comparison of Pearson-r correlation coefficients.

\begin{tabular}{lcc}
\hline \hline Expectation clusters & $\begin{array}{c}\text { Correlations of percentages of favorable responses with } \\
\text { Normalized FMCE gain } \\
(p \text { value })\end{array}$ & $\begin{array}{c}\text { Final exam score } \\
(p \text { value })\end{array}$ \\
\hline Precourse overall with effort & $0.310(0.000)$ & $0.343(0.000)$ \\
Precourse overall excluded effort & $0.341(0.000)$ & $0.377(0.000)$ \\
Postcourse overall with effort & $0.261(0.000)$ & $0.378(0.000)$ \\
Postcourse overall excluded effort & $0.281(0.000)$ & $0.426(0.000)$ \\
\hline \hline
\end{tabular}


published studies of American university students. The overall favorable expectation scores of students in two calculus-based introductory physics classes in Thailand had a significant correlation with student learning gains as measured by both conceptual and final exam tests. This is consistent with the work of Kortemeyer [13], Coletta and Phillips [15], and Dancy [16], who all found a positive correlation between student MPEX scores and their conceptual learning gains and final exam scores. The present results are also consistent with the work of Kortemeyer [13], who observed a small positive correlation of 0.01 between the MPEX effort cluster and final exam scores, and Dancy [16], who found no significant correlation between the MPEX effort cluster and final exam scores.

\section{CONCLUSION}

Our results showed that the students' precourse expectations as measured by MPEX are correlated with multiple measures of student learning in calculus-based introductory physics courses in Thailand. We found positive correlations between student expectations and conceptual learning gains and final exam scores. This is consistent with the findings of previous published studies of American university students. These are also consistent with the idea that student expectations influence their learning. Although positive correlations were observed overall, we found uncertainty in the correlations between the effort cluster with both conceptual learning gains and final exam scores $(p>0.05)$. This may be due to the limitation of the survey instrument we used, in that it might not measure the actual student efforts. We also saw stronger correlations of the student expectations and learning when the effort items were excluded from the MPEX survey. The results support the idea that the effort cluster does not accurately measure relevant student effort activities that the students are actually making to learn in an introductory physics course. These findings were clarified by the results of the student interviews.

\section{ACKNOWLEDGMENTS}

The authors would like to thank all the members of the Physics Education Network of Thailand (PENThai) for their many valuable discussions and suggestions. Special thanks must also go to Professor Ian Johnston of Uniserve Science, The University of Sydney, for his guidance and discussions on our first draft of this manuscript. We would also like to thank the Institute for Innovative Learning, Mahidol University, the Thailand Center of Excellence in Physics (ThEP), and the Institute for the Promotion of Teaching Science and Technology (IPST) for each providing support for this study.
[1] H. Lin, Learning physics vs. passing course, Phys. Teach. 20, 151 (1982).

[2] D. Hammer, Two approaches to learning physics, Phys. Teach. 27, 664 (1989).

[3] L. Lising and A. Elby, The impact of epistemology on learning: A case study from introductory physics, Am. J. Phys. 73, 372 (2005).

[4] D. B. May and E. Etkina, College physics students' epistemological self-reflection and its relationship to conceptual learning, Am. J. Phys. 70, 1249 (2002).

[5] E. F. Redish, J.M. Saul, and R.N. Steinberg, Student expectations in introductory physics, Am. J. Phys. 66, 212 (1998).

[6] B. K. Hofer and P. R. Pintrich, The development of epistemological theories: Beliefs about knowledge and knowing and their relation to learning, Rev. Educ. Res. 67, 88 (1997).

[7] M. Schommer, A. Crouse, and N. Rhodes, Epistemological beliefs and mathematical text comprehension: Believing it is simple does not make it so, J. Educ. Psychol. 84, 435 (1992).

[8] G. Qian and D. Alvermann, Relationship between epistemological beliefs and conceptual change learning, Read. Writ. Q. 16, 59 (2000).

[9] K. S. Kitchener, Cognition, metacognition and epistemic cognition, Hum. Dev. 26, 222 (1983).
[10] W. K. Adams, K. K. Perkins, N. S. Podolefsky, M. Dubson, N.D. Finkelstein, and C.E. Wieman, New instrument for measuring student beliefs about physics and learning physics: The Colorado Learning Attitude about Science Survey, Phys. Rev. ST Phys. Educ. Res. 2, 010101 (2006).

[11] K. K. Perkins, W. K. Adams, S. J. Pollock, N.D. Finkelstein, and C.E. Wieman, in Proceeding of the Physics Education Research Conference, Sacramento, $C A$, 2004, edited by J. Marx, P. Heron, and S. Franklin (AIP, New York, 2005), p. 61.

[12] R. K. Thornton and D. R. Sokoloff, Assessing student learning of Newton's laws: The Force and Motion Conceptual Evaluation and the Evaluation of Active Learning Laboratory and Lecture Curricula, Am. J. Phys. 66, 338 (1998).

[13] G. Kortemeyer, Correlations between student discussion behavior, attitudes, and learning, Phys. Rev. ST Phys. Educ. Res. 3, 010101 (2007).

[14] D. Hestenes, M. Wells, and G. Swackhamer, Force Concept Inventory, Phys. Teach. 30, 141 (1992).

[15] V. Coletta and J. Phillips, in Proceedings of the AAPT Conference, Salt Lake, Utah, 2005, http://myweb.lmu.edu/ jphillips/PER/AAPT-summer05.pdf.

[16] M. Dancy, in Proceedings of the Physics Education Research Conference, Boise, Idaho, 2002 (unpublished). 
[17] C. Soankwan, N. Emarat, K. Arayathanitkul, and R. Chitaree, Physics Education in Thailand, International Commission on Physics Education Newsletter 54, 6 (2007).

[18] E.F. Redish, Teaching Physics With The Physics Suite (John Wiley \& Sons, Hoboken, NJ, 2003), Chap. 5, p. 105.

[19] J. M. Saul, Ph.D. thesis, Maryland University, 1998.

[20] S. Maroney, http://www.wiu.edu/users/mfsam1/ TeamTchg.html.

[21] P. Narjaikaew, N. Emarat, and B. Cowie, The effect of guided note taking during lectures on Thai university students' understanding of electromagnetism, Res. Sci. Technol. Educ. 27, 75 (2009).

[22] Examples of worksheets and final-exam papers, http:// neural.sc.mahidol.ac.th/?q=firstyear/scpy157_2553.
[23] E.F. Redish, Student Expectations in University Physics: Using the Maryland Physics Expectation Survey, http://www.physics.umd.edu/perg/expects/ usempex.htm.

[24] N. Emarat, K. Arayathanitlkul, C. Soankwan, R. Chitaree, and I.D. Johnston, The effectiveness of the Thai traditional teaching in the introductory physics course: A comparison with the US and Australian approaches, Callaborate 9, 1 (2002).

[25] R. R. Hake, Interactive-engagement versus traditional methods: A six-thousand student survey of mechanics test for introductory physics course, Am. J. Phys. 66, 64 (1998).

[26] J. D. Marx and K. Cummings, Normalized change, Am. J. Phys. 75, 87 (2007). 